\title{
Grounding e autopossessão em atividades da educação física
}

http://dx.doi.org/10.11606/1807-5509202000040699

\author{
Diane Ferraz Lopes Rocha* \\ Pierre Normando Gomes-da-Silva* \\ Fernando Cézar Bezerra de Andrade* \\ Ana Raquel Oliveira França*
}

\section{Resumo}

Analisou-se a autopossessão inerente ao grounding em aulas de Educação Física Escolar com discentes do $5^{\circ}$ ano de escola municipal paraibana. Define-se grounding como fluxo de excitação energética, sentido como vibrações céfalo-caudais descendentes e ascendentes, envolvendo o contato com emoções e sua expressão (autoexpressão), cujo gradual autocontrole denomina-se autopossessão. No grounding, tomase consciência corporal de si, reconhecendo emoções e as expressando adequadamente (autopossessão). Resulta disto o reconhecimento cognitivo do grounding e de sua autopossessão, chamado conscientização. Com metodologia qualitativa, coletaram-se dados por observações diretas e entrevistas semiestruturadas durante aulas de Educação Física. Aplicou-se análise de conteúdo categorial aos resultados, constatandose presença de autoexpressão, deficiência em autopossessão e, portanto, na conscientização. Concluiu-se pela importância de conhecer o grounding como conceito e processo empírico a fim de que referenciem o planejamento pedagógico de atividades nas aulas de Educação Física Escolar, a fim de promover e elevar o nivel de autopossessão e conscientização do alunado.

PalavRAs-Chave: Bioenergética; Educação Física Escolar; Grounding; Autopossessão.

\section{Introdução}

Esta pesquisa se baseia na análise de práticas da Educação Física Escolar, à luz de um fundamento da Bioenergética - o grounding, definido como o contato do indivíduo com o seu corpo, com o solo onde pisa e com sua realidade interna e externa Lowen $^{1}$. A Análise Bioenergética enxerga, nas tensôes musculares crônicas perceptíveis em posturas e movimentos corporais, significados capazes de comunicar, por, uma história de sintomas, conflitos e defesas que, segundo Lowen ${ }^{2}$, "diminuem a vitalidade da pessoa e rebaixam sua energia" 2 .

Para a Bioenergética, recalques de desejos estáo associados ao medo (consciente ou inconsciente) de punição pelas consequências de ter impulsos realizados. Assim, o recalque associa- se fortemente a processos de enrijecimento muscular que, gradualmente, se torna crônico, mantendo as defesas psíquicas em ação. Outro traço decorrente da cronicidade do enrijecimento é sua automatização: o indivíduo perde a consciência do estado de tensão e passa a operar integrando, na medida do possível, consequências da rigidez: dor, espasticidade, dessensibilização, que afeta, inclusive, seu funcionamento, fisiológica e psicologicamente considerado - explicando o "mover- se automatizado, sem atenção ao mundo" Gomes-da Silva ${ }^{3}$, promovendo "um desenraizamento [...] encoberto sob a proteção da autoeficácia, do autoconceito e da autocerteza, caracterizando-se numa compreensão mediana do mundo" GoMes-DA SILVA (p. 169) 3 .

Tudo isso configura um distanciamento de si, justamente oposto ao grounding e nocivo, a 
ponto de resultar em patologias psíquicas, como a esquizofrenia, em que se dá a cisão radical entre consciência e realidade e, por conseguinte, a incoerência mais evidente entre sentimentos, pensamentos e ações. Caso a identificação com o corpo e seus sentimentos esteja comprometida, a consciência de si, decorrente do processo de reconhecimento cognitivo do grounding e da adequada expressáo das emoçóes a ele associadas - denominada autopossessão - é distorcida ou tornada inacessível.

Ora, isso traz, obviamente, consequências para a convivência: quem não toma consciência de si dificilmente terá condições de reconhecer e respeitar outras pessoas. Donde, a consideração pelo outro também será negativamente afetada. Do ponto de vista social, inclusive, é possível que o sujeito compense a falta dessas habilidades com atitudes autoritárias e violentas que seguem na contramão de um ambiente que prime por buscar indivíduos que tendam a ser autônomos. É o que ocorre, por exemplo, quando se constatam práticas de violência na escola, como o bullying. A experiência relatada por TenóRIO ${ }^{4}$, ao considerar uma intervenção recorrendo à análise bioenergética de longo prazo, ressalta um aspecto importante decorrente dessa desconexão entre emoçôes, cognição e corporalidade na escola, manifesta na violência, e confirma o caráter comunicacional da violência na escola, que carece de grounding para seu acolhimento: "essas atitudes [refere-se a condutas de violência discente na escola] eram praticadas como um pedido de ajuda, como forma de adquirir independência e estabelecer limites ou de lidar com a sexualidade".

Se devidamente modificados, a história pessoal e o ambiente social permitem que o indivíduo tenha mais capacidade de estar em contato com sua realidade interna e externa e de se expressar. Quanto menos tensóes musculares, mais grounded, e quanto mais embasados o educador e o educando estiverem, mais terão possibilidades de se comunicar de forma expressiva, com movimentos criativos. Como afirma TenóRio ${ }^{4}$ ao tratar dos resultados de sua intervençáo, no tocante aos ganhos do alunado, "adquirir uma percepção de si trouxe um aumento do repertório de compreensão dos seus sentimentos e também das questôes pertinentes ao convívio".

Do ponto de vista corporal, o processo energético do grounding supóe que haja um fluxo de excitação através do corpo, da cabeça aos pés (e vice-versa). $\mathrm{O}$ grounding caracteriza-se pela postura ereta, não rígida, coluna equilibrada, articulação dos joelhos ligeiramente fletidas, peso do corpo na parte arredondada dos pés, à frente, e centramento no abdômen Lowen ${ }^{2}$. Nesse sentido, pode- se promover o grounding por meio de exercícios que desenvolvam tal postura, como aqueles pensados por Low $\mathrm{EN}^{2}$, que agem justamente em prol daquele contato consigo e com o mundo, levando à lucidez e à segurança. Não obstante a importância da consciência, atividades espontâneas e habituais também podem, sem a consciência individual sobre esse processo, promover o grounding - o que, por vezes, pode ocorrer em atividades esportivas ou artísticas, como o balé, cuja(o) dançarina(o) mantém-se em frequente contato com o chão Tord Figueras 5 .

Assim, o grounding e seus efeitos - a autoexpressão emocional e a autopossessão (que implica no controle da autoexpressão) - sáo táo importantes que, se estivermos embasados no próprio corpo e no chão, diferentemente de "andar sempre nas nuvens", teremos mais condiçóes de responsabilizarmonos pela realidade do mundo. Nesse sentido, "a autopossessáo pode ser verificada pela capacidade que a pessoa tem de responder adequadamente às situaçóes de sua vida" LoweN ${ }^{6}$. Isso aumenta, significativamente, as chances de coerência e de coesão psicocorporais, devido à sintonia entre mover(-se), sentir(-se) e expressar(-se). Nesse contexto, o indivíduo visa compreender a si mesmo e ao mundo de modo criativo, tendo como base a percepção corpo-espaço-tempo.

Então, a autoexpressão emocional e a autopossessáo aumentam as chances do movimento criativo, que permite "novos prazeres e significados à vida” LoweN ${ }^{7}$, em três níveis - sensação, percepção e simbolização. Resulta disso a conscientização - que, como foi afirmado, é entendida enquanto reconhecimento cognitivo do processo de grounding e de seus efeitos benéficos.

Com o recurso à reflexão verbal pelo alunado, é possível concorrer para o desenvolvimento da autonomia - no seu sentido mais amplo, isto é, relacionada à conscientização (a partir do grounding). O movimento e a ação, coordenados e eficientes, podem ser desenvolvidos também na situação de ensino-aprendizagem, constituindo-se a base da autopossessão Lowen ${ }^{6}$. Compreende-se a importância desta última relação: como lembram Ferreira e Del Prette ${ }^{8}$, uma das aprendizagens mais importantes consiste na formação da habilidade de expressar-se de forma coerente com o contexto da interaçáo e a emoção experimentada - o que supõe a regulação da expressividade emocional, 
desenvolvida, inclusive, pelo feedback apresentado por outras pessoas na interação. Do ponto de vista aqui apresentado, a autopossessão é um dos efeitos mais diretamente associados a um feedback dessa natureza.

Pode-se também afirmar que o grounding e sua autopossessão convergem para as metas da Pedagogia da Corporeidade GoMES-DA-SiLvA ${ }^{3}$, segundo a qual a aprendizagem envolve a corporeidade humana e suas aptidôes sensório-motoras, que dependem da unidade interdependente de fatores biológicos, socioculturais e psicológicos. Por aquela pedagogia, as estratégias de ensino e de aprendizagem, de um modo geral, em especial, as da Educação Física, devem promover situaçóes em que os alunos sintam e pensem. As atividades da Educação Física Escolar, de acordo com a articulação possível entre Pedagogia da Corporeidade e Análise Bioenergética, aumentam as chances para que o alunado entre em contato com suas angústias, seus desejos e suas frustraçóes.

O caráter não intencional da promoção do grounding, por um lado; e os benefícios decorrentes de seu favorecimento, por outro, ressaltam a possibilidade de utilizar-se o olhar da Bioenergética no campo da Educação Física Escolar. Neste trabalho, portanto, analisando situaçóes nas aulas de Educação Física, em que, não intencionalmente, foi algumas vezes identificada a promoção do grounding em atividades propostas pela docente, foi investigado se a autopossessáo era vivenciada por discentes.

Perguntou-se: a autopossessão foi vivenciada nas aulas de Educaçáo Física em uma turma de $5^{\circ}$ ano de uma escola municipal paraibana? Para respondêla, objetivou-se identificar o grounding e seu aspecto da autopossessão nas mencionadas aulas; de modo específico, objetivou-se fazer um levantamento das atividades praticadas nas aulas de Educação Física por alunos do $5^{\circ}$ ano do Ensino Fundamental; aplicar um protocolo de observação para registrar as atividades discentes durante as citadas aulas, a partir do proposto pela professora responsável; entrevistar discentes após aquelas aulas; e analisar atividades em aulas de Educação Física, à luz das características do grounding.

Para considerar o conjunto dos dados coletados, adotou-se como premissa geral de análise a necessidade da inclusão intencional do grounding enquanto princípio organizador de atividades de ensino-aprendizagem na sequência didática de aulas de Educação Física. Uma vez atendida tal premissa, presume-se que o grounding, intimamente associado à autopossessão, incrementa a vitalidade e a criatividade discentes, concorrendo para a saúde na escola.

\section{Método}

Os dados apresentados neste artigo foram coletados pela primeira autora durante sua pesquisa de Mestrado FERRAz ROCHA ${ }^{9}$. Visto que aqui são considerados apenas dados coletados através de entrevistas semiestruturadas, descreve-se a seguir como esta estratégia foi empregada. Com ela, foram considerados os dados matizados de sentido Снizzotті ${ }^{10}$.

As entrevistas permitiram o acesso aos significados e emoçóes que as observaçóes - outra estratégia adotada por RocHA ${ }^{9}$ - não poderiam revelar por si sós. Após observação por 300 minutos (distribuídos ao longo de um mês de aulas, com duas horas-aula por semana, num total de seis horas gravadas em vídeo e áudio, com apoio de um protocolo para identificar e registrar o grounding nas aulas), foram entrevistados 14 discentes entre dez e quatorze anos, selecionados conforme os seguintes critérios de inclusão: que não portassem deficiência mental que os impedisse de comunicar-se verbalmente e de forma articulada; que estivessem matriculados(as) nas turmas pesquisadas; fossem autorizados(as) pelo responsável para participar da pesquisa; que estivessem presentes nos momentos de observação. Os participantes foram identificados pela primeira letra da palavra grounding e por número (logo, G1 a G14).

Enveredou-se pela análise de conteúdo de BARDIN ${ }^{11}$, cuja técnica de tratamento dos dados orienta a escolher categorias analíticas. As categorias analíticas são "as que retêm, historicamente, as relaçóes sociais fundamentais, servindo como guias teóricos e balizas para o conhecimento de um objeto nos seus aspectos gerais. Elas comportam vários graus de generalização e de aproximação" Minayo (p. 178) ${ }^{12}$. No caso das entrevistas, aqui consideradas, o "grounding" foi definido como única categoria analítica. Com isso, agregaram-se os já referidos indicadores de grounding através da leitura da obra de Lowen ${ }^{1-2}$, 6-7,13-17, RochA $^{18}$ e WeIGAND ${ }^{19}$. Quanto às categorias operacionais BARDIN ${ }^{11}$ - "construídas com a finalidade de aproximação ao objeto de pesquisa (na sua fase empírica), devendo ser apropriadas ou construídas com a finalidade de permitir a observação e o trabalho 
de campo" Minayo (p. 179) ${ }^{12}$-, foram obtidas a "realidade interna" e a "realidade externa", implícitas nos indicadores, por exemplo, da seguinte forma: o chão que serve de apoio é realidade externa; as sensações corporais decorrentes da participação na atividade são componentes da realidade interna; o colega com quem se joga faz parte da realidade externa; e assim por diante. Essas categorias serviram como elementos para interpretar os dados.

Para BARDIN ${ }^{11}$, a unidade de contexto corresponde ao segmento da mensagem, cujas dimensóes (superiores às da unidade de registro) são ótimas para que se possa compreender a significação exata da unidade de registro. Para a categoria operacional "realidade externa", a unidade de contexto foi a "aula de Educação Física"; já para a categoria operacional "realidade interna", tratouse da própria "unidade corporal individual".

Por sua vez, cada unidade de registro, que consiste na "unidade de significação codificada e correspondente ao segmento de conteúdo considerado unidade de base" BARDIN (p. 134) ${ }^{11}$, correspondeu aos descritores agrupados pelos indicadores de grounding. Assim, percepçóes, sentimentos, posturas, movimentos e falas de discentes serviram para constituir os indicadores antes listados.

A entrevista visou aprofundar o acesso a dados

\section{Resultados}

Como se afirmou, a autopossessão concerne à regulação emocional para a expressão adequada ao contexto da interação. Nesse sentido, um indivíduo com autopossessão é alguém que exprime seus sentimentos, fazendo-o de modo assertivo - inclusive para o caso de sentimentos considerados negativos (como a raiva, a dor, o medo). Para referir-se à autopossessáo, é necessário tratar dos sentimentos, de sua expressão e seu controle, portanto.

No caso da turma estudada, boa parte das falas transcritas evidenciou ser a raiva um sentimento mais recorrentemente experimentado. Sinto raiva porque os meninos ficam mexendo, chamando
de perebento e veado (G2).

Sinto raiva quando os meninos ficam mexendo com a pessoa dá raiva também... Xingando os outros, fica chamando os povo [sic] de "baleia" (G14).

Às vezes, quando os meninos ficam brincando comigo, subjetivos autodescritos, como a percepção, ligada à noção de grounding. Portanto, após dois itens definidores do perfil discente (idade, gênero) e seis questóes (das quais, cinco abertas e uma com múltiplas alternativas), visamos à descrição verbal de sensações, percepçôes e emoçóes decorrentes da participação em atividades propostas pela professora em que poderíamos identificar a presença do grounding. As falas foram literalmente importante para que se pudesse identificar a autopossessão e a conscientização, visto que tais níveis de realização do grounding supóem uma apropriação subjetiva da experiência. Não à toa, como se pode ver a partir de agora, nos resultados, a descrição subjetiva foi essencial para a identificação dos significados e vivências atribuídos por discentes.

Em relação aos aspectos éticos da pesquisa, o projeto foi encaminhado ao Comitê de Ética do Hospital Universitário Lauro Wanderley/UFPB, para atender às consideraçôes éticas e aos preceitos da Resolução 196/96, do Conselho Nacional de Saúde, responsável pelas diretrizes e pelas normas que regulamentam as pesquisas que envolvem seres humanos. O projeto foi aprovado pelo comitê, tendo como número do parecer de aprovação: 223.742 no dia 19/03/2013, e assinado o termo de consentimento livre e esclarecido por todos os responsáveis pelos discentes.

mexendo com a pessoa. Discutindo, apelidando de "maga" (G6).

Essa raiva, todavia, era expressa de forma antissocial, em muitas situaçóes caracterizáveis como violência, já que transparecia nas agressóes entre colegas: mais particularmente em relação às ofensas verbais, G2, G6 e G14 confirmaram o caráter violento das agressóes, ao referirem-se a sofrimentos associados a uma autoimagem ferida em funçáo de algum traço fisionômico ("pereba"), do peso ("baleia", "mag[r]a") ou mesmo identitário ("veado").

Também G4 disse sentir raiva "quando os meninos ficam xingando, chamando de mica [menina amiga] burra, cavala, burra" (G4). Ao falar do vínculo que tinha com sua amiga, G5 externou situaçóes de preconceito: "Eu tenho vínculo com G8, ela é minha melhor amiga, já estudei com ela há cinco anos. [...] Ficam falando da gente por trás, só porque pra onde eu vou, G8 vai e pra onde G8 vai, eu vou, ficam chamando a gente de sapatáo". 
Nesses trechos, seis discentes mencionaram seu sofrimento em razão das agressões de colegas: a autoexpressão, então, como condição anterior à autopossessão, verificou-se nas falas dos entrevistados. Eles sabiam o que sentiam e conseguiram falar disso. A questão, porém, estava na dificuldade em regular as próprias emoçóes e as dos outros. Alguns discentes, ao comentarem sobre suas reaçôes, indicaram reagir também agressivamente.

Às vezes, quando os meninos ficam mexendo comigo, eu já derrubei um pelo gogó. Eu peguei por aqui, ele falando da minha mãe, eu pequei aqui e derrubei. Ele disse: "Tá vendo como você é, G6?”. Ele começou a chorar. Ele não quer que fale da mãe dele, por que ele fala da minha? A mãe nem na escola tá, pra falar dela! Eu não posso ver ninguém falando da minha mãe, eu tenho ódio, raiva (G6).

Outro exemplo, retirado da fala de G11, acentua como o círculo vicioso da violência alimentava-se pela adoção, pelos agredidos, do padráo igualmente agressivo: "Os meninos ficam brincando de empurrar e eu vou empurrar [...]". Nesse sentido, as falas permitiram que se ressaltasse a falta de autopossessão no que concerne à expressão da raiva. Disso também se derivava a violência com que discentes se tratavam durante as aulas.

Deve-se ressaltar que, na experiência discente, não havia dispositivos institucionais que garantissem apoio a outras formas de reação, já que a disciplina escolar era baseada em procedimentos tradicionais (puniçóes negativas), sem a intervenção que proporcionasse um modelo positivo de resolução de conflitos: "quando a pessoa pede a bola e os outros não dá, aí a pessoa vai falar com a professora e ela faz que náo escuta a pessoa, aí dá uma raiva!" (G11).

\section{Discussão}

"Sentimos raiva porque nosso ser é diminuído. Ficamos zangados porque nos sentimos amedrontados e desagradáveis. E nossa raiva é proporcional ao nosso medo e à perda do si- mesmo", comenta LoweN ${ }^{20}$ (p. 140). Ora, em todas as falas citadas, há a referência à diminuição do eu, por traços de diferença (aparência, inteligência, orientação sexual). Não surpreende, então, que os processos descritos por LoweN ${ }^{20}$ subjazam à raiva sentida pelos discentes. A interpretação pela qual o medo de não ser (respeitável, humano, digno) e não pertencer (ao grupo de iguais ou mesmo à escola, por
Em função desses padrões emocionais mantidos pelas práticas sociais entre pares e pela própria escola, as atividades propostas durante as aulas de Educaçáo Física serviam de cenário para a repetição da experiência emocional que não ultrapassava, na maioria das vezes, a autoexpressão, sem autopossessão.

Além da raiva, o medo era presente. Por exemplo, na situação em que o aluno disse: "Quando os meninos jogam bola em mim forte de propósito, também não gosto quando joga um pro outro na roda, joga bola na barriga" (G5), identificou-se uma intenção de machucarem (G5, no caso). Essa prática causava medo - "no baleado, os meninos jogam com muita força, às vezes dáo até bicudo, tenho medo que bata na minha cara" (G6) - e raiva, quando "ficam com brincadeira de derrubar, brincadeira de mau gosto" (G6).

Verificou-se, em suma, na escola estudada, a presença de autoexpressão, mas não de indicadores suficientes para a autopossessão, o que levou a inferir a ausência do último nível necessário ao processo inteiro do grounding nas atividades da Educação Física. A constatação de violência na escola, com recorrência, ressalta a inadequada expressão da raiva - que, de resto, é uma emoção legítima, mas que, associada à agressão verbal ou física, evidencia a ausência do ajuste necessário à interação pró-social da emoção - donde, confirma a inexistência de autopossessão de modo completo, identificável na recusa da violência.

Pelas entrevistas, foram identificados comportamentos discentes ofensivos verbal e fisicamente, permitindo inferir padróes impulsivos - similares à descarga emocional - que, mesmo associados a alguma consciência de emoçóes (os discentes entrevistados sabiam reconhecer e falar da emoção), não contribuíam para a integração entre emoção, consciência e ação, própria à autopossessão.

exemplo) verifica-se muito pertinente.

Também deve ser mencionado que a raiva é um sentimento quente: "os sentimentos quentes estão relacionados ao amor, e isso inclui a raiva" LowEN (p. 209) ${ }^{16}$. Num ambiente menos favorável ao grounding, é compreensível que ela desemboque em violência, já que o desejo de base (ser amado) não encontra acolhimento suficiente e repercute como raiva (já que não sou amado, odeio). Por ser um sentimento associado à agressividade, caso esta seja mal dirigida (no sentido de condutas antissociais), a raiva será frequente 
e mal expressa.

Não à toa, segundo ANDrADE (p. 43) $)^{21}$, a violência "é uma patologia da agressividade [...]

o abuso da agressividade", de modo que ela se manifesta por "todas as variadas açóes em que se identifica, num contexto intersubjetivo, intencionalidade e desejo (inclusive inconsciente) de provocar dano ou mal a $\operatorname{outra}(s) \operatorname{pessoa}(s)$ ou a si mesmo(a)" ANDrade (p. 71)21.

A turma, em particular, e a escola, em geral, constituíam um contexto de muita violência verbal, com interaçóes claramente agressivas - no sentido violento deste adjetivo. $\mathrm{O}$ sentimento mais referido pelos sujeitos, a raiva, se pensado bioenergeticamente, implica numa onda de energia corporal que ativa os músculos para atacarem com intensidade. Sobre isso, LOWEN $^{16}$ afirma:

Para o ser humano, estar com raiva representa um surto de excitação ascendente, que sobe pelas costas e desce pelos braços, que agora estão energizados para brigar. A excitação também flui até o topo da cabeça e nos dentes caninos superiores, que então ficam energizados para morder [...] À medida que essa excitação flui através dos músculos das costas, eles se arqueiam, preparando-se para o ataque (p. 87) ${ }^{16}$

Em situação ideal, em que se promove o grounding, se for percebida pela consciência e houver contexto para sua elaboração através da mediação verbal (que também promove conscientizaçáo), a raiva sujeitar-se-á ao controle do ego, e a tensão gerada tem a possibilidade de ser aliviada de forma adequada.

Ao contrário, se a raiva não encontra níveis de elaboração mais conscientes e pró-sociais, ou mesmo se for reprimida em nível inconsciente LoweN ${ }^{16}$, ela oferecerá resistência à autopossessão, já que impelirá o sujeito a (re)agir sem pensar, sem dar significado a (e, consequentemente, sem controlar) impulsos defensivos agressivos.

No caso dos alunos pesquisados - mesmo que, naturalmente, dado o contexto escolar, sentimentos inconscientes não tenham sido objeto de estudo -, é provável que houvesse sentimentos reprimidos, inferência baseada em sua faixa etária (10 a 14 anos), tendo ultrapassado o período de seis a nove anos, quando, segundo $\mathrm{NAVARRO}^{22}$, se consolidam o caráter patológico e a couraça muscular a ele associada.

Por outro lado, notamos que existia muito sentimento gerado pelas próprias situaçôes de violência, que já ultrapassavam o nível de conflito, para o qual não se encontrava uma solução adequada, sem intervenção eficaz - até porque, como lembra $\mathrm{BACRI}^{23}$ a respeito do modelo escolar em geral, a própria instituição também criava condiçóes avessas ao grouding, à autoexpressão e à autopossessão.

A violência na escola supóe (e gera) raivas que, muitas vezes, não são devidamente expressas, nem servem à autoconsciência. Nesse sentido, sua presença indica importante falta de grounding a ser preenchida.

As situaçôes mencionadas pelos entrevistados deveriam ser objeto de intervençáo na aula de Educação Física, cuja base contivesse os princípios do grounding, e não, simplesmente, a condução do problema para a diretora, que, muitas vezes, só usa de seu poder para intervir. Se, como pretendem Tenório ${ }^{4}$ e Andrade (p. $71)^{21}$ - para quem a violência "é sobretudo portadora de significados culturalmente elaborados, [...] é mensagem e mensageira" -, caberia aos educadores e educadoras (como a professora da turma observada) incluir a reflexão sobre as situaçôes de violência vividas na instituição - e, também, nas aulas de Educação Física -, de modo a promover, pelo diálogo, conscientização e autopossessão. O grounding nas atividades da Educação Física certamente contribuiria para esse processo naquela turma.

"O exercício básico de grounding [...] possibilita aumentar o senso de segurança. Estar grounded é ter o seu lugar, é ser alguém e, quanto mais pudessem estar em contato consigo, maior a possibilidade de estarem em contato com o grupo", afirma'TENÓRIO ${ }^{4}$ (p. 55-56). Por esse crivo, a violência na escola lócus da pesquisa denunciava que muitos do alunado não se sentiam reconhecidos, nem em suas experiências subjetivas nem em seus lugares de identidade. Por conseguinte, não conseguiam manter contato consigo nem com os outros. Não havia possibilidade institucional suficiente para a autopossessão.

Se for certo que muitas mensagens fogem do nosso poder de interpretação, por causa dos seus elementos, por vezes, inconscientes, por exemplo, é certo também que o processo de ensino- aprendizagem, quando busca um ambiente onde se instigue o conhecimento de si, do outro e do mundo, de liberdade de expressão e, ao mesmo tempo, respeitoso de si e do outro e procura "despertar neles [no alunado] a consciência de suas responsabilidades e direitos na escola e na sociedade, ajudando-os a formar valores e habilidades sociais necessários à resolução não violenta de conflitos" Andrade (p. 93) 21 . Será um ambiente com autoconsciência, autoexpressão e autopossessão, elementos integrantes do grounding.

A couraça muscular, constituída pela totalidade da musculatura cronicamente enrijecida, acontece devido a um conflito entre exigências pulsionais e a realidade 
externa que as frustra. Para a Análise Bioenergética, se a expressão emocional dá-se sem a possibilidade de experimentar sentimentos ternos (como podem ser a alegria e a tristeza), ocorre um recalque dos desejos associados àqueles sentimentos, em decorrência do medo, consciente ou inconsciente, de ser punido por tais desejos. Para manter tal recalque, o indivíduo se enrijece e a defesa assume um caráter cronicamente operante e automático. No caso da raiva, muito associada à frustração por diferentes motivos, ela se instala com mais profundidade na couraça em situaçóes nas quais não há a possibilidade de verbalização.

A emoção da raiva é parte da função mais ampla de agressão, que literalmente significa "mover-se na direção de" [...] Podemos nos mover na direçấo de outra pessoa por amor ou raiva. Ambas as açôes são agressivas e ambas são positivas para o indivíduo Lowen (p. 86) ${ }^{16}$.

É preciso, no entanto, que a raiva (como o amor) seja canalizada de forma adequada. Para tanto, são necessárias a escuta e a fala. Desde muito pequenas, muitas crianças começam a aprender que náo vale a pena chorar, pois suas mães não virão, e se não forem escutadas na escola, o reforço estará dado, e o raciocínio será: "Não adianta falar".

Esse exercício de diálogo sobre o vivido é essencial para se refletir sobre a educação e valorizar o desenvolvimento da tomada de consciência e, consequentemente, o desenvolvimento de seres humanos mais livres e seguros para o diálogo, no sentido freireano. Segundo Guedes (p. 31) ${ }^{24}$, "o diálogo, na pedagogia freireana, não é simplesmente uma troca de ideias, conhecimentos e projetos, mas, antes de tudo, um compromisso com o outro e mais especificamente, com o outro 'oprimido', vulnerável humana, sócio e politicamente”. Portanto, o diálogo é o caminho para construir a conscientização.

Porém, como os dados revelaram, havia ainda um ambiente de muita desconfiança e tensão no cotidiano da turma pesquisada. Esse clima institucional gera tensões físicas, e convém lembrar que "as tensóes musculares crônicas que sufocam e aprisionam o espírito desenvolvem-se na infância em função da necessidade de controlar a expressão de emoçóes fortes, como medo, tristeza e raiva” LowEN (p. 44) ${ }^{16}$.

Se a turma encontrava-se num período ainda muito aberto à formação, influenciável sob o ponto de vista da socialização, e que, normalmente, os pais e os professores frustram os impulsos espontâneos da criança, entende-se por que tanta raiva foi referida nos resultados.

Outro importante elemento, bem específico da
Educação Física naquela escola, foi o dos jogos competitivos. No caso, os sujeitos fizeram referência, entre outros, ao "baleado" (também chamado por “queimada”). Para a Bioenergética, esses jogos são interessante oportunidade para o desenvolvimento do grounding. Contudo, tais jogos, como eram conduzidos nas aulas, não favoreciam a autopossessão, visto que derivavam em agressóes físicas e verbais mútuas. Basta lembrar os depoimentos de G5 e G6 para sublinhar o caráter eminentemente violento dos jogos, sem o cuidado docente para converter a expressão da agressividade em oportunidade para aprender o autocontrole emocional - logo, para desenvolver a autopossessão.

Noutra direção, pensando teoricamente a relação positiva entre competição e autopossessão, tem-se como exemplo o cabo de guerra Correia e Alves ${ }^{25}$. Esses exercícios, em que a Bioenergética foca a expressão dos sentimentos, por serem vigorosos e competentes, permitem que o corpo expresse sentimentos fortes, como raiva, ciúme e inveja que, normalmente, ficam reprimidos, e contribuem para que, quando os sentimentos guardados forem expressos, os conflitos interpessoais sejam resolvidos Correia e Alves ${ }^{25}$

No caso do cabo de guerra, além da experiência do vigor, há também a necessidade de respeitar regras, oponentes e, ao mesmo tempo, valorizar o grupo (a equipe com quem se compete). Há a possibilidade de aprender que a força física e as emoçóes a ela relacionadas podem ser muito construtivas, além de divertidas quando compartilhadas, sem o risco de destruir(-se).

Observando-se isso, reconhece-se que os jogos de competição, habituais nas aulas de Educação Física, podem e precisam ser melhor empregados. $\mathrm{O}$ que falta para isso é justamente valorizar as expressóes dos sentimentos e o diálogo. E como fazer isso nos exercícios durante as aulas? Estimular os discentes a fazerem vocalizaçóes durante os jogos é importante. Outra possibilidade é de propiciar aos discentes a expressão mais vigorosa de sentimentos envolvidos em determinadas situaçóes do próprio jogo e em outros momentos da aula, quando eles podem trabalhar em duplas, em subgrupos ou com todo o grupo.

A Bioenergética utiliza exercícios em que a mandíbula seja desbloqueada, e a expressão dos olhos, os dentes e os braços sejam estimulados. "Também podemos usar as pernas para expressar sentimentos de raiva, como o chute [...] A expressão 'espernear' a respeito de alguma coisa significa protestar contra ela. Todos nós temos muito a protestar, no que diz respeito ao que fizeram conosco, e é importante expressar esse protesto" 
Lowen (p. 104) ${ }^{16}$. Esses são seguimentos de nosso corpo em que a raiva é expressa. Porém é importante que não seja uma prática mecânica e compulsiva.

Geralmente, depois de aplicar os exercícios de expressáo da energia raivosa, vêm as atividades de confiança. "Trabalhamos os anéis [da couraça muscular], dando ênfase ao tratamento dos conflitos interpessoais e à expressão da energia raivosa. Introduzimos as atividades de confiança” CoRreia e Alves (p. 150) ${ }^{25}$. É importante ressaltar o princípio pelo qual mais vale instigar a criatividade de cada um para provocar situaçôes em que haja a expressão de sentimentos raivosos e posteriormente vivências de afeto e confiança acompanhadas de uma pedagogia que sistematize açóes docentes pelas quais os discentes tenham espaço de autoexpressão adequada e dialoguem sobre isso, com $\mathrm{o}$ intuito de alcançarem a autopossessão. Dessa forma, aumentar-se-á a probabilidade de autoconhecimento e autodomínio, contribuindo para que discentes e docentes tornem-se mais embasados, enraizados, com uma maior capacidade para responsabilização perante os desafios da vida, visto que estarão identificados com seus corpos e sentimentos e com autodomínio para expressá-los com pertinência.

Com a presente pesquisa, estabeleceram-se paralelos entre a prática da Bioenergética e as situaçóes propostas por docentes em aulas de Educação Física. No decorrer do processo de ensino- aprendizagem, nas aulas de Educação Física, o grounding desenvolve-se de forma inconsciente e consciente, porquanto o processo consciente requer mais sistematizaçóes docentes para que os discentes tenham espaço de autoexpressão adequada e dialoguem sobre isso.

Caso tal princípio seja implementado, aumentará a probabilidade de autoconhecimento e de autodomínio, o que contribui para que discentes (e docentes) tornemse mais grounded, enraizados e sejam bem mais capazes de responder às responsabilidades e aos desafios que se lhes apresentam, pelo fato de estarem identificados com seus corpos e sentimentos e com autodomínio para canalizá-los, a fim de serem expressos com pertinência.

A pesquisa evidenciou que, na turma do $5^{\circ}$ ano da escola pública investigada, durante as aulas de Educação Física que foram observadas e, após elas, a partir do conteúdo das entrevistas feitas com discentes, estes necessitavam desenvolver, de forma mais efetiva, um estado de autopossessão, visto que muito da raiva que sentiam era em decorrência de situaçôes de violência na escola, que gerava um círculo vicioso em que o diálogo sobre o vivido era escasso, e o nível de consciência ainda náo estava integrado.

A expressão da tomada de consciência em nível verbal não foi devidamente valorizada - possivelmente devido à cisão corpo/mente que ainda caracteriza a formaçấo de docentes em Educaçáo Física Escolar, desabituados da função de ouvir e acolher a expressão discente e dirigi-la para a aprendizagem.

Dentro do recorte que fizemos para este trabalho, salienta-se a possibilidade de aplicar alguns fundamentos da Bioenergética como sugestão para as práticas de Educação Física: valorizar momentos em que os alunos sentem vibraçóes no corpo; desconstruir o axioma da postura militarizada; promover a conscientização do padrão respiratório; incluir no planejamento didático, exercícios que destaquem a autoexpressão pela projeção vocal e alonguem a musculatura; ouvir e estimular a fala e o diálogo reflexivo.

Tomando-se a perspectiva aqui adotada, a Educação Física Escolar concorrerá para o grounding e, com ele, para a autonomia e a assertividade discente, com respeito à capacidade de autorregulaçáo do ser humano, graças à autoconsciência decorrente do contato com seus corpos e a realidade interna, de um lado, e a realidade social, externa, de outro - num processo que tende a unir cognição, pensamento, emoção e existência e aumenta a probabilidade de a autorregulaçáo contribuir para o processo de ensino-aprendizagem com a noção de identidade e de um sentido mais integrado, para que haja mais conexão e se desconstrua a desconexáo perceptiva dos dias de hoje.

Observou-se que, apesar de estarem presentes a alegria e o prazer, há, em alguma medida, um adoecimento nas relaçóes naquela escola. Ressalta-se, no entanto, que, através dos princípios do grounding, é possível buscar a saúde que, para a Bioenergética, é um equilíbrio a ser conquistado continuamente. $\mathrm{Na}$ comunicação corporal, quando os sinais estão sendo alvo de atenção e se recorre ao grounding, aumentam-se as chances de que a vitalidade e o equilibrio corporais contribuam para o bom funcionamento cognitivo, afetivo e social na escola.

Quanto menos tensôes musculares, mais grounded e mais embasados os envolvidos no processo de ensinoaprendizagem estiverem, mais terão condiçóes de se comunicar de forma expressiva e de perceber o que o outro está expressando. Assim, todo o processo de ensino- aprendizagem será facilitado. LowEN ${ }^{\top}$ defende que o grounding "leva a pessoa a entrar em contato com suas pernas por aumentar o sentimento nelas, o que depois proporciona maior segurança e apoio para todos os exercícios de autoexpressão" (p. 104) $)^{7}$. Enxergamos aqui um dos caminhos para que todos os envolvidos nesse processo possam aumentar sua capacidade de se autoexpressar e de atingir a autopossessão eficazmente. 
Por essa razão, é necessário um processo de expressão adequada, sem culpas impostas, evitando a repressão de sentimentos. Só assim, estaremos prevenindo novas couraças musculares, pois a raiva reprimida não desaparece. "As crianças atuarão (act-out) o impulso proibido contra crianças menores, machucando-as deliberadamente." LowEN (p. 92) ${ }^{16}$.

Para o(a) docente de Educação Física Escolar, deixase a recomendação de que se mantenha em grounding, a fim de poder contribuir para a autopossessão de seu alunado. Na medida em que o(a) professor(a) de Educação Física estiver atento(a) a si mesmo(a), capaz de autoexpressão emocional e autopossessão, poderá lidar melhor com seus próprios sentimentos de raiva, medo e tristeza, tão comuns em ambientes tensos como aquele apresentado pela turma pesquisada.

É comum que docentes sintam-se desamparados em cenários como o descrito, em função de não se sentirem hábeis, como mediadores de conflito relacional, por exemplo, para "lidar com o medo dos alunos e a insegurança de ministrar uma aula." MARTiny et al., (p. 576 ${ }^{26}$. Daí, também, a importância de incluir, na formação inicial, o grounding como princípio de preparação pessoal e profissional do(a) docente de Educação Física Escolar, a orientá-lo(a) em sua carreira.

De modo geral, pensa-se, aqui, no estímulo à expansão da conscientização do corpo como um todo, com o objetivo de combater os processos defensivos. As possibilidades dessa estimulação são inúmeras, assim como os exercícios bioenergéticos desenvolvidos por LoweN ${ }^{16}$ nas práticas educativas psicocorporais realizadas nas escolas, o exercício atento da inter-relação vivencial, que melhora a qualidade de vida, por meio de um trabalho preventivo, pedagógico e interventivo com a comunidade escolar, onde náo haja dicotomia entre a educação física e a mental.

Dessa forma, a Educação Física Escolar estará mais integrada, com mais possibilidade de promover o grounding e, com ele, um processo de ensinoaprendizagem mais assertivo, já que, atento à complexidade de elementos que integram tal processo, o indivíduo terá mais possibilidade de se integrar.

\title{
Agradecimentos
}

Apoio da Coordenação de Aperfeiçoamento de Pessoal de Nível Superior (CAPES).

\begin{abstract}
Grounding and self-possession in activities of physical education.

It was analyzed the self-possession associated to the grounding in physical education classes with 5th year's students of a Paraiba's municipal school. The grounding is defined as an energy excitement flow, felt as descending and ascending cerebrospinal vibrations, involving the contact with emotions and their expression (self-expression), whose gradual self-control is called self- possession. In grounding, the body takes self-consciousness of itself, recognizing emotions and expressing them appropriately (self-possession). The result of this is the cognitive recognition of grounding and its self-possession, called awareness. With qualitative methodology, the data was collected by direct observations and semi-structured interviews during physical education classes. It was applied analysis of categorical content to the results, noting the presence of self-expression, deficiency in self-possession and therefore, in awareness - which was not included intentionally in the educational planning. It was concluded the importance of knowing conceptually and empirically the grounding, so that it becames a reference for physical education classe's activities in pedagogical planning, in order to promote and raise the level of students' selfposession and conciousness
\end{abstract}

KEYwORDS: Bioenergetics; Physical education classes; Grounding; Selfposession. 


\section{Referências}

1. Lowen A. Bioenergética. Tradução de Maria Sílvia Mourão Netto. São Paulo: Summus, 1982.

2. Lowen A. Exercícios de Bioenergética: o caminho para uma saúde vibrante. Tradução de Vera Lúcia Marinho, Suzana Domingues de Castro. São Paulo: Ágora, 1985.

3. Gomes-da-Silva PN. A corporeidade do movimento: por uma análise existencial das práticas corporais. In: Hermida FJ, Zoboli F, organizadores. Corporeidade e Educação. João Pessoa: Editora Universitária da UFPB, 2012. p. 169. 4. Tenório S. Projeto Hora do Blá - uma intervenção da Análise Bioenergética Focada no âmbito escolar. In: Fiorini $\mathrm{H}$ et al. Clínica social e psicoterapia corporal: um conjunto de experiências em Análise Bioenergética Focada. São Paulo: Instituto de Análise Bioenergética de São Paulo, 2016.

5. Tord Figueras P. Grounding: concepto y usos em Danza Movimiento Terapia (DMT). Barcelona, 2013. 71 p. Dissertação (Mestrado em DMT). Facultat de Ciencias de l'Educació, Universitat Autònoma de Barcelona, 2013. 6. Lowen A. O corpo traído. Tradução de George Schlesinger. São Paulo: Summus, 1979.

7. Lowen A. Prazer: uma abordagem criativa da vida. Tradução de Ibanez de Carvalho Filho. São Paulo: Summus, 1984.

8. Ferreira BC, Del Prette, ZAP. Programa de expressividade facial de emoçóes e habilidades sociais de crianças deficientes visuais e videntes. Psicol: Reflex Crít. 2013,26(2):327-338.

9. Ferraz Rocha DL. Grounding em aulas de educação física escolar: uma análise pela bioenergética. $2014.97 \mathrm{f}$. Dissertação (Mestrado em Educação) - Universidade Federal da Paraíba, João Pessoa, 2014.

10. Chizzotti A. Pesquisa em ciências humanas e sociais. São Paulo: Cortez, 1995.

11. Bardin L. Análise de conteúdo. Tradução de Luís Antero Reto, Augusto Pinheiro. São Paulo: Ediçôes 70, 2011.

12. Minayo MCS. O desafio do conhecimento: pesquisa qualitativa em saúde. 12. ed. São Paulo: Hucitec, 2010.

13. Lowen A. O corpo em terapia da abordagem bioenergética. Tradução de Maria Sílvia Mourão Netto. São Paulo: Summus, 1977.

14. Lowen A. O corpo em depressão: as bases biológicas da fé e da realidade. Tradução de Ibanez de Carvalho Filho. São Paulo: Summus, 1983.

15. Lowen A. espiritualidade do corpo. Tradução de Paulo César de Oliveira. São Paulo: Cultrix, 1990.

16. Lowen A. Alegria: a entrega ao corpo e à vida. Tradução de Maria Sílvia Mourão Netto. São Paulo: Summus, 1997.

17. Lowen A. Uma vida para o corpo: autobiografia de Alexander Lowen. Tradução de Maria Sílvia Mourão Netto. São Paulo: Summus, 2007.

18. Rocha BS. Brincando com o corpo. São Paulo: Arte \& Ciência, 2005.

19. Weigand O. Grounding e autonomia. São Paulo: Edições e Produções Person, 2006.

20. Lowen A. Medo da vida. São Paulo: Summus, 1986.

21. Andrade FCB. Tornar-se uma lição permanente: psicodinâmica da competência inter-relacional do (a) educador (a) na gestão de conflitos e na prevenção da violência na escola. João Pessoa, 2007. 220p. Tese (Doutorado em Educação) - Departamento de Educação, Universidade Federal da Paraíba, Paraíba, 2007.

22. Navarro F. Caracterologia pós-reichiana. Tradução Cibele dos Santos Coelho. São Paulo: Summus, 1995.

23. Bacri APR. Influência dos bloqueios corporais na Educação. Uberlândia, 2005. 115 p. Dissertação (Mestrado em Educação) - Departamento de Educação, Universidade Federal de Uberlândia, Minas Gerais, 2005.

24. Guedes EC. Educação e alteridade: uma meta-arqueologia da educação a partir de Emmanuel Lévinas e Paulo Freire, 2007 - 181 folhas. Tese (Doutorado em Educação). Programa de Pós- graduação em Educação, Universidade Federal da Paraíba, João Pessoa, 2007.

25. Alves J, Correia GWB. O corpo nos grupos: experiências em análise bioenergética. 3. ed. Recife: Ed. Libertas, 2010 .

26. Martiny LE et al. O que eu transformaria? Muita coisa: os saberes e os não saberes docentes presentes no estágio supervisionado em Educação Física. Rev Educ Física/UEM.2011,22(4):569-581. 
Grounding e autopossessão em atividades da educação física

ENDEREÇO
Diane Ferraz Lopes Rocha

Diane Ferraz Lopes Rocha

Rua Bacharel Manoel Pereira Diniz, 202/ 205
58051-900 - J oão Pessoa - PB - Brasi

Submetido: 09/01/2018

E-mail: dianeferrazlopes@yahoo.com.br

Aceito: 11/ 07/ 2018 